\title{
BULLETIN
}

\section{INTERNATI0 NAL}

DES

\section{SOCIETLS IOE LA CROIX-ROUGE}

publié par le

COMITÉ INTERNATIONAL

FONDATELIR IDE GETTE INSTITUTION

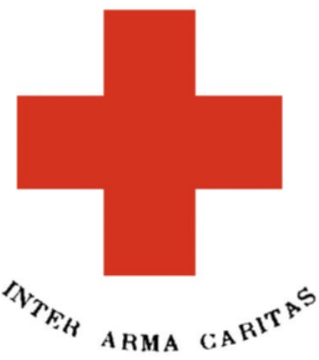

GENEVE

IMPRIMERIE I. SOULLIER, GITÉ, 19-21

1910 


\section{COMITÉ INTERNATIONAL}

Pour adresse: M. Gustave ADon.

En hiver : rue de l'Athénée, 8 ; en été : à Cologny, près Genève

Les membres dı Comité sont:

MM. Moynier, Gustave, Président d'honneur de l'institut de droit international, Associé étranger de l'Institut de France, Président.

Ador, Gustave, Conseiller national, $1^{\text {tx }}$ Vice-Président.

Odier, Edouard, Ministre de Suisse à Saint-Pétershourg, 2e Vice-Président.

Moynier, Adolphe, Consul de Belgique, Trésorier.

D'Espine, Adolphe, Dr mẻd., Professeur à l'Université, Associé étranger de l'Académie de Médecine de Paris, Secrétaire.

Favre, Camille, Colonel.

Ferrière, Frédéric, Dr-méd.

Gautier, Alfred, Professeur à l'Universilé et juge à la Cour de cassation.

Naville, Edouard, Professeur à l'Université, Associé étranger de l'Institut de France.

Direction et Adninistration du Bulletin: Des Gouttes, Paul, Docleur en droit, avocat, Corraterie, 24, Genève.

\section{ADRESSES DES COMITÉS CENTRAUX}

ALLEMAGNE. - Comité central des associations allemandes de la Croix-Rouge, Roonstrasse, 9, à Berlin, N. W. 40.

ARGENTINE (RÉPUBLIQUE) - Comité central de la CroixRouge argentine, Moreno 3365, à Buenos-Ayres.

AUTRICHE. - Société autrichienne de la Croix-Houge, 'Tuchlauben, 6 , à Vicme.

BADE. - Comité général de la Société badoise de la CroixRouge, Gartenstrasse, 49, à Carlsruhe.

BAVIĖRE. - M. le Comte ne Drechser, président du Comité central de la Société bavaroise de la Croix-Houge, à Munich.

BELGIQUE* - Secrétariat général de la Croix-Rouge de Belgique, Hòtel Ravenstein, Salle VII, à Bruxelles.

BULGARIE. - M. J.-L. Gú́choff, président de la Société bulgare de la Croix-Rouge, à Sofia.

CHILI. - Comité central de la Croix-Rouge chilienne, PuntaArenas, territoire de Magellan.

CUBA. - Société nationale cubaine de la Croix-Rouge, 18, Tejadillo, La Havane.

DANEMARK. - Société de la Gruix-Rouge (Det Rode Kors), a Copenhague K.

ESPAGNE. - Société espagnole de la Groix-Rouge, Plaza del Progreso, 1, à Madrid.

ÉTATS-UNIS. - Central Commiltee of the American National Red Cross, Koom 341, State, War and Navy Building, Washington D.C.

FRANCE. - Comité central de la Croix-Rouge française, rue Matignon, 19, à Paris $8^{\mathrm{e}}$. 